\title{
Conduction Abnormalities after Transcatheter Aortic Valve Implantation and Diastolic Dysfunction
}

\author{
Ofir Priesler Simon Biner Ariel Finkelstein Yoav Michowitz \\ Department of Cardiology, Tel Aviv Sourasky Medical Center, Sackler Faculty of Medicine, Tel Aviv University, \\ Tel Aviv, Israel
}

\section{Keywords}

Transcatheter aortic valve implantation - Conduction abnormalities · Diastolic dysfunction

\begin{abstract}
Objectives: Transcatheter aortic valve implantation (TAVI) is frequently associated with the development of conduction abnormalities. We assessed the effect of conduction abnormalities on diastolic function following TAVI. Methods: In total, 101 consecutive post-TAVI patients were included, each with echocardiographic follow-up at 1 and 6 months. Diastolic properties were correlated with the occurrence of a long PR interval and wide QRS, and their change from baseline. The measured diastolic parameters included E/A ratio, $E$ wave deceleration time, $E$ wave to $e^{\prime}$ ratio, left atrial (LA) volume, and systolic pulmonary artery pressure (SPAP). The clinical outcome was all-cause mortality. Results: Overall, TAVI was associated with a consistent decrease in SPAP at the 1-and 6-month follow-up. LA volumes were increased at 1 month post-TAVI in patients with a wide compared to normal QRS ( $p=0.03)$ and at 6 months in patients with a normal compared to prolonged PR $(p=0.03)$. PR prolongation above 40 ms was associated with lower SPAP at the 1- but not 6-month follow-up. Survival was not influenced by conduc-
\end{abstract}

\section{KARGER}

() 2016 S. Karger AG, Basel

E-Mail karger@karger.com

www.karger.com/crd tion abnormalities. Conclusions: TAVI is associated with a reduction in SPAP. A postprocedural wide QRS and normal PR interval may unfavorably influence the left-sided filling performance, resulting in an increased LA volume. Other diastolic parameters, as well as survival, are not significantly affected by postprocedural conduction abnormalities.

(c) 2016 S. Karger AG, Basel

\section{Introduction}

Left ventricular (LV) diastolic dysfunction is reported in approximately $50 \%$ of patients with aortic stenosis and a normal systolic ejection performance, and in $100 \%$ of those with depressed LV function [1]. Left bundle branch block (LBBB) is associated with an impaired systolic and diastolic function [2-4], while PR prolongation is associated with a decreased ejection fraction [5]. In patients with severe aortic stenosis, transcatheter aortic valve implantation (TAVI) may result in improved LV diastolic properties [6-8]. On the other hand, TAVI may cause conduction disturbances including PR prolongation and

Dr. Priesler and Dr. Biner contributed equally to this work. 
LBBB [9-11]. New-onset LBBB after TAVI can be the cause of failure of the LV ejection fraction to improve in short- and long-term follow-up, despite the procedural success [12], and similarly may mitigate the impact of the procedure on LV diastolic performance. The aim of the study was to evaluate the relation between conduction disturbance and diastolic function in patients undergoing TAVI.

\section{Methods}

Our study population included consecutive patients undergoing transfemoral TAVI for the treatment of severe aortic valve stenosis using the Edwards Sapien/Sapien XT prosthesis (Edwards Lifesciences, Irvine, CA, USA) or the Medtronic CoreValve prosthesis (MCV; Medtronic, Minneapolis, MN, USA) at a tertiary university hospital between 2009 and 2012. The institutional ethics committee approved the study.

The inclusion criteria for TAVI were a logistic EuroSCORE $>20$, porcelain aorta, previous chest radiation, a logistic EuroSCORE $>10$, and 1 of the following: cachexia [13], the need for assistance in basic daily activities [14], or previous open heart surgery. Eligibility for TAVI was determined by the institutional Heart Team, comprising an interventional cardiologist, echocardiologists, and a cardiothoracic surgeon.

Patients undergoing TAVI were enrolled in a prospective registry recording procedural information as well as clinical and echocardiographic data collected at baseline, 30 days, and 6 months. Measurement of diastolic parameters was not routine in all patients, and therefore only patients in whom these parameters were measured were included in the current study. All patients without exclusion criteria were included in the current study.

The exclusion criteria for this study were as follows: atrial fibrillation during echocardiographic and electrocardiogaphic data collection, patients with a permanent pacemaker (either implanted before the TAVI procedure or after it due to AV block), and patients with incomplete echocardiographic or electrocardiographic (ECG) data.

Transthoracic echocardiographic data were obtained with a standardized protocol. LV linear dimensions were measured in the parasternal long-axis view. Early (E) transmitral filling peak velocity, atrial (A) transmitral filling peak velocity and deceleration time (DT) were obtained with pulsed wave Doppler sample at the tip of the mitral valve leaflet [15]. Early velocity of the septal and lateral aspects of the mitral annulus was measured using tissue Doppler imaging. Mitral annulus velocity $\left(\mathrm{e}^{\prime}\right)$ was defined as the average of septal and lateral velocities [15]. Left atrial (LA) volume was determined using the biplane area-length or dimension-length methods [16]. Systolic pulmonary artery pressure (SPAP) was estimated using tricuspid regurgitation velocity as well as appearance and respiratory changes of inferior vena cava [17]. Echo Doppler indexes of aortic stenosis severity included the maximal velocity (Vmax) across the aortic valve, the mean pressure gradient and the aortic valve area (AVA), calculated using the standard continuity equation [16]. Severe aortic stenosis was defined as $V \max >4 \mathrm{~m} / \mathrm{s}$, mean pressure gradient $>40 \mathrm{~mm} \mathrm{Hg}$, and AVA $<1.0 \mathrm{~cm}^{2}[18]$.

Conduction Abnormalities after TAVI and Diastolic Dysfunction
Table 1. Baseline demographic and clinical characteristics

\begin{tabular}{lc}
\hline Age, years & $83 \pm 5$ \\
Male & $28(27.7)$ \\
Height, cm & $161 \pm 8$ \\
Weight, kg & $70 \pm 14$ \\
Body surface area, ${ }^{2}$ & $1.7 \pm 0.3$ \\
Diabetes mellitus & $27(26.7)$ \\
Dyslipidemia & $74(73.3)$ \\
Hypertension & $93(92.1)$ \\
Peripheral vascular disease & $6(5.9)$ \\
Past stroke & $9(8.9)$ \\
Systolic heart failure & $15(14.9)$ \\
Previous coronary bypass grafting & $10(9.9)$ \\
Logistic EuroSCORE & $15 \pm 8.5$ \\
\hline
\end{tabular}

Data are presented as the mean \pm SD or $n(\%)$.

Table 2. ECG parameters

\begin{tabular}{lccl}
\hline & Baseline & $\begin{array}{l}\text { 1 month after } \\
\text { TAVI }\end{array}$ & $p$ value \\
& & & \\
\hline PR interval, ms & $175.31 \pm 36.64$ & $184.38 \pm 39.02$ & 0.09 \\
QRS width, ms & $86.39 \pm 20.01$ & $93.66 \pm 24.38$ & 0.021 \\
QT interval, ms & $424.23 \pm 57.88$ & $420.77 \pm 53.4$ & 0.65 \\
QTc, ms & $440 \pm 0.05$ & $440 \pm 0.05$ & 0.49 \\
RR interval, ms & $943.02 \pm 150.59$ & $911.78 \pm 156.92$ & 0.15 \\
\hline
\end{tabular}

For ECG data we used simultaneous ECG recordings performed during the echocardiographic study. ECG intervals were obtained with traces performed at the time of mitral inflow pulsed Doppler or mitral annulus tissue Doppler imaging. The values of PR, QRS, and QT, were obtained at baseline and 30 days after TAVI. Corrected QT (QTc) was calculated using the Bazzet formula [19]. The clinical endpoint was overall survival.

\section{Statistical Analysis}

Continuous normally distributed parameters are presented as the mean \pm SD and were compared using the Student $t$ test. All $p$ values were 2 -sided and $p<0.05$ was considered statistically significant. Correlations were assessed with the Pearson correlation test. Event-free survival was calculated according to the KaplanMeier method. All data were analyzed with JMP System software version 8.0 (SAS Institute Inc., Cary, NC, USA).

\section{Results}

Of the 344 consecutive patients who underwent TAVI, 141 patients were excluded due to incomplete or absent echo-Doppler data, 53 because of atrial fibrillation, 34 
Table 3. Echocardiographic diastolic parameters

\begin{tabular}{lccccl}
\hline & Baseline & $\begin{array}{l}\text { 1 month after } \\
\text { TAVI }\end{array}$ & $p$ value & $\begin{array}{l}\text { 6 months after } \\
\text { TAVI }\end{array}$ & $p$ value \\
\hline E/A & $1.07 \pm 0.71$ & $0.97 \pm 0.57$ & 0.16 & $0.97 \pm 0.65$ & 0.34 \\
MVDT, ms & $240.92 \pm 82.66$ & $241.19 \pm 80.61$ & 0.98 & $265.93 \pm 84.53$ & 0.056 \\
E/e' & $19.24 \pm 7.07$ & $20.99 \pm 10.42$ & 0.29 & $18.68 \pm 7.67$ & 0.47 \\
LA volume, mL & $85.28 \pm 27.25$ & $84.93 \pm 27.82$ & 0.7 & $80.52 \pm 24.77$ & 0.35 \\
SPAP, mm Hg & $41.48 \pm 13.84$ & $37.63 \pm 13.1$ & 0.014 & $35.3 \pm 11.93$ & 0.005 \\
\hline
\end{tabular}

due to poor-quality ECG recordings, and 15 due to the presence of a permanent pacemaker. Of note, 40 patients developed a complete AV block following TAVI. These patients were already excluded due to incomplete data or the presence of a permanent pacemaker, which was also an exclusion criterion. Thus, the study population consisted of 101 patients, of whom 30 were implanted with the Edwards Sapien/Sapien XT prosthesis and 71 with the MCV prosthesis. Table 1 presents the baseline demographic and clinical characteristics of the entire cohort.

\section{Echocardiographic and ECG Measurements}

Table 2 presents ECG measurements at baseline assessment and at 1 month after TAVI. There was a significant prolongation in QRS width $(p=0.021)$ and no significant change of other variables at 1 month after TAVI compared to baseline.

The diastolic echo-Doppler parameters at baseline, 1 and 6 months after TAVI are presented in Table 3. There was a progressive reduction in SPAP at 1 month $(p=$ $0.014)$, and at 6 months after the procedure $(p=0.005)$. In addition, there was a trend towards a prolongation in E wave DT at 6 months compared to baseline $(p=0.056)$. All other parameters showed no significant change over time during the study period.

\section{Correlation between the ECG and Diastolic}

\section{Echocardiographic Parameters}

In order to better understand the interaction between ECG intervals and diastolic parameters, we performed the following correlations: (1) postprocedural ECG (PR and QRS) intervals and diastolic parameters post-TAVI at 1 and 6 months, and (2) changes $(\Delta)$ in ECG intervals and changes in diastolic parameters at 1 and at 6 months.

At 1 month, there was a weak, albeit significant negative correlation between QRS width and E wave DT $(r=-0.21$, $p=0.03)$, and, at 6 months, there was a weak, positive correlation between $\Delta \mathrm{PR}$ with $\Delta \mathrm{E} / \mathrm{e}^{\prime}(r=0.28, p=0.01)$.

\section{Analysis according to $P R$ Interval and $\triangle P R$}

We next compared diastolic parameters in patients with a normal $(<200 \mathrm{~ms})$, and those with a long $(\geq 200 \mathrm{~ms})$ PR interval 1 month after TAVI (Table 4). There was no significant difference in diastolic echocardiographic parameters between the 2 groups at 1 month. However, at 6 months after TAVI, patients with a long PR exhibited a higher E/A ratio $(p=0.03)$ and lower LA volume $(p=$ $0.03)$.

We also stratified the patients to those who prolonged their PR interval above or below $40 \mathrm{~ms}$ compared to baseline. Patients with PR prolongation $\geq 40 \mathrm{~ms}$ had a lower SPAP at 1 month post-TAVI. However, at the 6-month echocardiographic follow-up this difference was no longer observed.

\section{Analysis according to $Q R S$ Interval and $\triangle Q R S$}

We compared diastolic parameters in patients with a narrow $(<120 \mathrm{~ms})$ and wide $(\geq 120 \mathrm{~ms})$ QRS complex (Table 5). Patients with a wide compared to narrow QRS had larger LA $(p=0.03)$ measurements at 1 month postTAVI. However, at 6 months this difference in LA volume was no more evident. A second stratification was of patients who prolonged their QRS compared to baseline ( $\triangle \mathrm{QRS} \geq 40$ or $<40 \mathrm{~ms}$ ). There was no significant difference between the 2 groups.

\section{Conduction Disturbance according to Valve Type}

The distributions of prolongation in PR or QRS $(\geq 40$ $\mathrm{ms})$ and absolute prolonged PR ( $\geq 200 \mathrm{~ms})$ or QRS ( $\geq 120$ ms) were not different between the 2 valve types ( $p=n$.s. for all calculations).

\section{Survival Rates}

Finally, survival analysis was performed in patients with normal and long PR, $\triangle \mathrm{PR}$ above or below $40 \mathrm{~ms}$, narrow and wide QRS, and $\triangle \mathrm{QRS}$ above or below $40 \mathrm{~ms}$. The mean follow-up was $1,102 \pm 315$ days (median 1,108 
Table 4. Diastolic measurements 1 and 6 months after TAVI stratified to PR interval (absolute value and $\Delta P R) 1$ month after TAVI

\begin{tabular}{lcccccc}
\hline & $\begin{array}{l}\mathrm{PR}<200 \mathrm{~ms} \\
(n=71)\end{array}$ & $\begin{array}{l}\mathrm{PR} \geq 200 \mathrm{~ms} \\
(n=30)\end{array}$ & $p$ value & $\begin{array}{l}\Delta \mathrm{PR}<40 \mathrm{~ms} \\
(n=82)\end{array}$ & $\begin{array}{l}\Delta \mathrm{PR} \geq 40 \mathrm{~ms} \\
(n=19)\end{array}$ & $p$ value \\
\hline 1 month & & & & & & \\
E/A & $0.95 \pm 0.54$ & $0.93 \pm 0.58$ & 0.39 & $0.92 \pm 0.53$ & $1.02 \pm 0.62$ & 0.52 \\
MVDT, ms & $236.55 \pm 76.62$ & $252.12 \pm 89.85$ & 0.89 & $239.56 \pm 81.68$ & $248.06 \pm 77.79$ & 0.69 \\
E/e' & $21.4 \pm 10.66$ & $20.02 \pm 8.35$ & 0.55 & $20.32 \pm 10.16$ & $23.61 \pm 8.93$ & 0.22 \\
LA volume, mL & $84.03 \pm 26.47$ & $79.08 \pm 27.57$ & 0.41 & $82.01 \pm 25.82$ & $85.35 \pm 31.46$ & 0.64 \\
SPAP, mm Hg & $37.67 \pm 12.8$ & $33.85 \pm 10.71$ & 0.19 & $37.96 \pm 12.6$ & $29.73 \pm 7.72$ & 0.018 \\
RR interval, ms & $894.23 \pm 152.67$ & $953.33 \pm 161.59$ & 0.08 & $902.68 \pm 160.64$ & $951.05 \pm 136.66$ & 0.23 \\
\hline 6 months & & & & & & \\
E/A & $0.88 \pm 0.31$ & $1.24 \pm 1.13$ & 0.03 & $0.92 \pm 0.48$ & $1.24 \pm 1.14$ & 0.09 \\
MVDT, ms & $257.11 \pm 78.66$ & $289.3 \pm 96.7$ & 0.15 & $270.83 \pm 85.89$ & $245.29 \pm 78.04$ & 0.31 \\
E/e' & $18.72 \pm 7.33$ & $18.58 \pm 8.8$ & 0.95 & $19.11 \pm 7.57$ & $16.99 \pm 8.1$ & 0.36 \\
LA volume, mL & $84.21 \pm 23.31$ & $70.89 \pm 26.39$ & 0.03 & $80.51 \pm 23.72$ & $80.55 \pm 30.02$ & 1 \\
SPAP, mm Hg & $36.23 \pm 12.28$ & $32.95 \pm 10.95$ & 0.31 & $34.93 \pm 11.93$ & $37.18 \pm 12.34$ & 0.57 \\
\hline
\end{tabular}

Table 5. Diastolic measurements 1 and 6 months after TAVI stratified to QRS interval (absolute value and $\Delta Q R S$ ) 1 month after TAVI

\begin{tabular}{lcccccc}
\hline & $\begin{array}{l}\text { QRS }<120 \mathrm{~ms} \\
(n=79)\end{array}$ & $\begin{array}{l}\text { QRS } \geq 120 \mathrm{~ms} \\
(n=22)\end{array}$ & $p$ value & $\begin{array}{l}\Delta \mathrm{QRS}<40 \mathrm{~ms} \\
(n=89)\end{array}$ & $\begin{array}{l}\Delta \mathrm{QRS} \geq 40 \mathrm{~ms} \\
(n=12)\end{array}$ & $p$ value \\
\hline 1 month & & & & & \\
E/A & $0.99 \pm 0.62$ & $0.94 \pm 0.46$ & 0.66 & $0.95 \pm 0.56$ & $0.91 \pm 0.48$ & 0.85 \\
MVDT, ms & $243.51 \pm 82.89$ & $228.03 \pm 66.25$ & 0.35 & $240.18 \pm 82.05$ & $249.60 \pm 70.53$ & 0.73 \\
E/e' & $20.33 \pm 8.92$ & $22.48 \pm 13.26$ & 0.34 & $20.69 \pm 9.99$ & $22.84 \pm 10.09$ & 0.51 \\
LA volume, mL & $81.19 \pm 28.32$ & $93.51 \pm 24.93$ & 0.03 & $82.63 \pm 26.98$ & $82.34 \pm 26.03$ & 0.97 \\
SPAP, mm Hg & $37.4 \pm 12.85$ & $38.14 \pm 13.88$ & 0.8 & $36.49 \pm 12.19$ & $36.30 \pm 13.33$ & 0.96 \\
RR interval, ms & $902.85 \pm 158.5$ & $943.86 \pm 150.22$ & 0.28 & $910.39 \pm 159.68$ & $922.08 \pm 140.49$ & 0.81 \\
\hline 6 months & & & & & & \\
E/A & $0.90 \pm 0.51$ & $1.17 \pm 0.84$ & 0.06 & $0.98 \pm 0.67$ & $0.84 \pm 0.23$ & 0.64 \\
MVDT, ms & $264.97 \pm 83.03$ & $261.3 \pm 90.44$ & 0.86 & $266.66 \pm 84.89$ & $257.83 \pm 87.63$ & 0.81 \\
E/e' & $18.85 \pm 7.67$ & $19.56 \pm 11.66$ & 0.75 & $18.41 \pm 7.73$ & $22.23 \pm 6.39$ & 0.29 \\
LA volume, mL & $81.91 \pm 28.06$ & $85.3 \pm 27.8$ & 0.61 & $80.42 \pm 25.07$ & $81.63 \pm 23.02$ & 0.9 \\
SPAP, mm Hg & $34.79 \pm 11.38$ & $37.9 \pm 13.07$ & 0.31 & $35.63 \pm 12.18$ & $30.00 \pm 5.10$ & 0.36 \\
\hline
\end{tabular}

days). As shown in Figure 1, there was no significant difference in overall survival between patients stratified by PR interval, or between patients with narrow versus wide QRS or $\triangle \mathrm{PR}$ and QRS above or below $40 \mathrm{~ms}$.

\section{Discussion}

In this study, we report the relation between conduction disturbances and diastolic function in post-TAVI patients. We found that patients may develop conduc- tion disturbance represented as QRS prolongation. This finding has been widely described before [6-8] and is explained by traumatic damage of the implanted valve to the His and left bundle branch, which penetrate the membranous septum a few millimeters below the right and noncoronary cusp [11]. Postprocedural PR prolongation have also been reported by several research groups [20,21]. However, in the current study only an insignificant trend to PR prolongation was found. This difference may be explained by the relatively small sample size. 


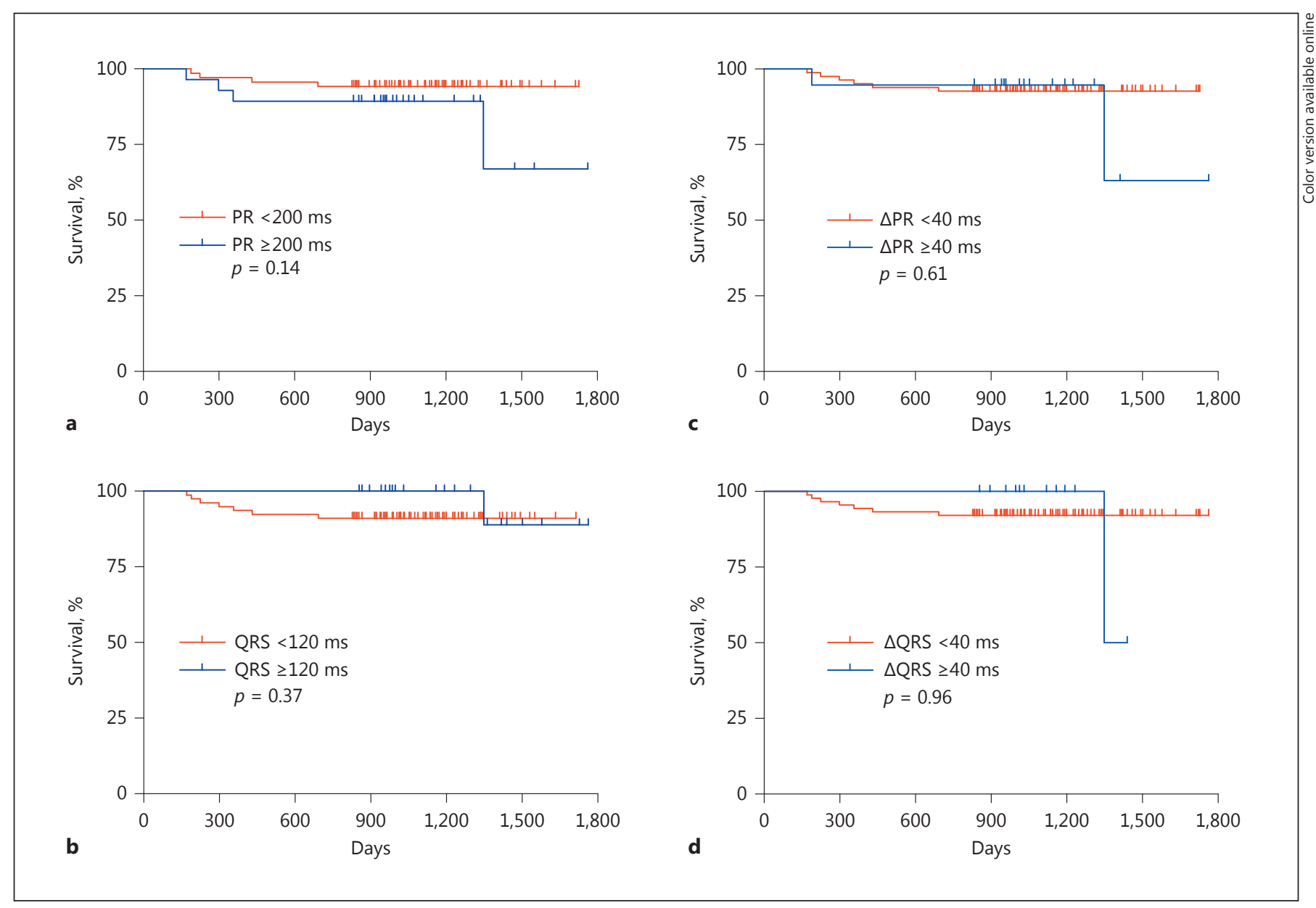

Fig. 1. Kaplan-Meier cumulative survival curves stratified according to long versus normal PR (a), wide versus narrow QRS (b), $\triangle \mathrm{PR}$ above or below $40 \mathrm{~ms}$ (c), and $\triangle \mathrm{QRS}$ above or below $40 \mathrm{~ms}$ (d).

Evaluation of the echocardiographic variables showed a reduction in SPAP. In the setting of TAVI, this finding is suggestive of an improved left-sided loading condition and is consistent with previous reports, demonstrating improved LV filling properties [9-11]. Hoffman et al. [22] analyzed 90 TAVI patients, of whom 39 (43\%) developed a new QRS widening. LVEF improved only in patients without new conduction defects. Urena et al. [23] showed that LBBB post-TAVI is associated with a lack of improvement in LVEF, and a poorer functional status. None of the abovementioned studies, or other studies [22, 24-26] to the best of our knowledge, evaluated the influence of conduction abnormalities on diastolic properties post-TAVI.

Our study demonstrated a lower LA volume and elevated $\mathrm{E} / \mathrm{A}$ ratio in patients with a longer $\mathrm{PR}$ at 6 months post-TAVI. This finding is somewhat unexpected and merits further validation in future studies, as long $\mathrm{PR}$ is associated with a shorter LV diastolic filling time. A partial explanation may be related to our cutoff of $200 \mathrm{~ms}$ for defining long PR. Whether or not a higher cutoff would better demonstrate the effect of shorter diastolic filling cannot be answered by the current study. It is also important to stress that we found a trend for a longer RR interval in patients with a longer $\mathrm{PR}$, which might explain the improvement in diastolic indices.

A higher LA volume was also demonstrated at 1 but not at 6 months after TAVI in patient with a wide QRS. This finding is consistent with the negative influence on LV filling performance.

Several studies have reported the relationship between LA volume and diastolic function following TAVI. Spethmann et al. [27] reported an acute improvement in the reservoir and conduit function of the LA accompanied by 
improvement of LV diastolic function within 8 days of the procedure. Aslan et al. [28] reported that TAVI is associated with improved LA appendage function, especially in patients with a marked diastolic dysfunction. According to our findings, these positive improvements in LA dimensions and function may be attenuated early by the development of wide QRS.

In order to evaluate whether the change in conduction, which is caused by the TAVI procedure itself, and not only the absolute values of PR and QRS may affect diastolic parameters, we divided the patients to those with and without $\mathrm{PR}$ or QRS prolongation compared to baseline. Except for a lower SPAP at 1 month but not at 6 months after the procedure in patients who experienced $\mathrm{PR}$ prolongation, no other significant change in diastolic parameters was observed. This may suggest that $\triangle \mathrm{PR}$ and $\triangle$ QRS do not significantly affect diastolic parameters post-TAVI.

In the current study, most diastolic parameters, except for LA volume and SPAP at 1 month, were not influenced by conduction abnormalities. Furthermore, we were unable to identify a strong and reliable direct correlation between conduction indices and their changes during follow-up and diastolic function indices and their changes. Also, and most importantly, no survival difference was found between patients with or without conduction abnormalities or prolongation following the procedure.

\section{Limitations}

The small sample size precluded us from subanalyzing the net effect of different conduction disturbances without the influence of others. For example, separately analyzing patients with a long or normal PR interval, but with a comparable RR interval or QRS width. Also, other powerful variables like patient age, comorbidities, and paravalvular leak may have a significant effect on diastolic function, possibly masking the effect of conduction disturbances.

In conclusion, in this study LA volumes and SPAP at 1 month were found to be mildly influenced by conduction abnormalities following TAVI. No clear and significant relationships were found between conduction abnormalities and other diastolic parameters. A possible explanation is that, on the one hand, conduction disturbance impairs diastolic function, whilst on the other hand, TAVI improves it, making the net effect on diastolic function is null.

\section{Conflict of Interest}

Dr. Finkelstein acts as a TAVI proctor and receives consultation fees from Medtronic Cardiovascular (Minneapolis, MN, USA) and Edwards Lifesciences (Irvine, CA, USA). All other authors declare having no potential conflicts of interest.

\section{References}

1 Hess OM, Villari B, Krayenbuehl HP: Diastolic dysfunction in aortic stenosis. Circulation 1993;87:IV73-IV6.

2 Littmann L, Symanski JD: Hemodynamic implications of left bundle branch block. J Electrocardiol 2000;33(suppl):115-121.

3 Prinzen FW, Peschar M: Relation between the pacing induced sequence of activation and left ventricular pump function in animals. Pacing Clin Electrophysiol 2002;25:484-498.

4 Peschar M, de Swart H, Michels KJ, Reneman RS, Prinzen FW: Left ventricular septal and apex pacing for optimal pump function in canine hearts. J Am Coll Cardiol 2003;41:12181226.

5 Mautner RK, Phillips JH: Atrioventricular and intraventricular conduction disturbances in aortic valvular disease. South Med J 1980; 73:572-578.

6 Gonçalves A, Marcos-Alberca P, Almeria C, Feltes G, Rodríguez E, Hernández-Antolín RA, Garcia E, Maroto L, Fernandez Perez C, Silva Cardoso JC, Macaya C, Zamorano JL: Acute left ventricle diastolic function improvement after transcatheter aortic valve im- plantation. Eur J Echocardiogr 2011;12:790797.

7 Gotzmann M, Lindstaedt M, Bojara W, Mügge A, Germing A: Hemodynamic results and changes in myocardial function after transcatheter aortic valve implantation. Am Heart J 2010;159:926-932.

8 Costantino MF, Galderisi M, Dores E, Innelli P, Tarsia G, Di Natale M, Santoro C, De Stefano F, Esposito R, de Simone G: Parallel improvement of left ventricular geometry and filling pressure after transcatheter aortic valve implantation in high risk aortic stenosis: comparison with major prosthetic surgery by standard echo Doppler evaluation. Cardiovasc Ultrasound 2013;11:18.

9 Calvi V, Puzzangara E, Pruiti GP, Conti S, Di Grazia A, Ussia GP, Capodanno D, Tamburino C: Early conduction disorders following percutaneous aortic valve replacement. Pacing Clin Electrophysiol 2009; 32:S126-S130.

10 Roten L, Wenaweser P, Delacrétaz E, Hellige G, Stortecky S, Tanner H, Pilgrim T, Kadner A, Eberle B, Zwahlen M, Carrel T, Meier B,
Windecker S: Incidence and predictors of atrioventricular conduction impairment after transcatheter aortic valve implantation. Am J Cardiol 2010;106:1473-1480.

11 Piazza N, Onuma Y, Jesserun E, Kint PP, Maugenest AM, Anderson RH, de Jaegere PP, Serruys PW: Early and persistent intraventricular conduction abnormalities and requirements for pacemaking after percutaneous replacement of the aortic valve. JACC Cardiovasc Interv 2008;1:310-316.

12 Wilczek K, Reguła R, Bujak K, Chodór P, Długaszek M, Gąsior M: Conduction disturbances after transcatheter aortic valve implantation procedures - predictors and management. Adv Interv Cardiol 2016;12:203211.

13 Evans WJ, Morley JE, Argilés J, Bales C, Bara$\cos$ V, Guttridge D, Jatoi A, Kalantar-Zadeh K, Lochs H, Mantovani G, Marks D, Mitch WE, Muscaritoli M, Najand A, Ponikowski P, Rossi Fanelli F, Schambelan M, Schols A, Schuster M, Thomas D, Wolfe R, Anker SD: Cachexia: a new definition. Clin Nutr 2008; 27:793-799.
Conduction Abnormalities after TAVI and Diastolic Dysfunction
Cardiology 2017;137:36-42 DOI: $10.1159 / 000452706$ 
14 Lee DH, Buth KJ, Martin BJ, Yip AM, Hirsch GM: Frail patients are at increased risk for mortality and prolonged institutional care after cardiac surgery. Circulation 2010;121: 973-978.

15 Nagueh SF, Appleton CP, Gillebert TC, Marino $\mathrm{PN}, \mathrm{Oh} \mathrm{JK}$, Smiseth $\mathrm{OA}$, Waggoner $\mathrm{AD}$, Flachskampf FA, Pellikka PA, Evangelista A: Recommendations for the evaluation of left ventricular diastolic function by echocardiography. J Am Soc Echocardiogr 2009;22:107133.

16 Tsang TS, Barnes ME, Bailey KR, Leibson CL, Montgomery SC, Takemoto Y, Diamond PM, Marra MA, Gersh BJ, Wiebers DO, Petty GW, Seward JB: Left atrial volume: important risk marker of incident atrial fibrillation in 1655 older men and women. Mayo Clin Proc 2001; 76:467-475.

17 Rudski LG, Lai WW, Afilalo J, Hua L, Handschumacher MD, Chandrasekaran K, Solomon SD, Louie EK, Schiller NB: Guidelines for the echocardiographic assessment of the right heart in adults: a report from the American Society of Echocardiography endorsed by the European Association of Echocardiography, a registered branch of the European Society of Cardiology, and the Canadian Society of Echocardiography. J Am Soc Echocardiogr 2010;23:685-713.

18 Baumgartner H, Hung J, Bermejo J, Chambers JB, Evangelista A, Griffin BP, Iung B, Otto CM, Pellikka PA, Quiñones M; American Society of Echocardiography; European Association of Echocardiography: Echocardiographic assessment of valve stenosis: EAE/ ASE recommendations for clinical practice. J Am Soc Echocardiogr 2009;22:1-23.

19 Garson A Jr: How to measure the QT interval - what is normal? Am J Cardiol 1993;72: 14B-16B.
20 Roten L, Stortecky S, Scarcia F, Kadner A, Tanner H, Delacrétaz E, Meier B, Windecker S, Carrel T, Wenaweser P: Atrioventricular conduction after transcatheter aortic valve implantation and surgical aortic valve replacement. J Cardiovasc Electrophysiol 2012; 23:1115-1122.

21 Rubín JM, Avanzas P, del Valle R, Renilla A, Ríos E, Calvo D, Lozano I,Anguera I, DíazMolina B, Cequier A, Morís de la Tassa C: Atrioventricular conduction disturbance characterization in transcatheter aortic valve implantation with the CoreValve prosthesis. Circ Cardiovasc Interv 2011;4:280-286.

22 Hoffmann R, Herpertz R, Lotfipour S, Aktug Ö, Brehmer K, Lehmacher W, Autschbach R, Marx N, Lotfi S: Impact of a new conduction defect after transcatheter aortic valve implantation on left ventricular function. JACC Cardiovasc Interv 2012;5:1257-1263.

23 Urena M, Webb JG, Cheema A, Serra V, Toggweiler S, Barbanti M, Cheung A, Ye J, Dumont E, DeLarochellière R, Doyle D, Al Lawati HA, Peterson M, Chisholm R, Igual A, Ribeiro HB, Nombela-Franco L, Philippon F, Garcia del Blanco B, Rodés-Cabau J: Impact of new-onset persistent left bundle branch block on late clinical outcomes in patients undergoing transcatheter aortic valve implantation with a balloon-expandable valve. JACC Cardiovasc Interv 2014;7:128-136.
24 Urena M, Mok M, Serra V, Dumont E, Nombela-Franco L, DeLarochellière R, Doyle D, Igual A, Larose E, Amat-Santos I, Côté M, Cuéllar $\mathrm{H}$, Pibarot $\mathrm{P}$, de Jaegere $\mathrm{P}$, Philippon F, Garcia del Blanco B, Rodés-Cabau J: Predictive factors and long-term clinical consequences of persistent left bundle branch block following transcatheter aortic valve implantation with a balloon-expandable valve. J Am Coll Cardiol 2012;60:1743-1752.

25 Tzikas A, van Dalen BM, van Mieghem NM, Gutierrez-Chico JL, Nuis RJ, Kauer F, Schultz C, Serruys PW, de Jaegere PP, Geleijnse ML: Frequency of conduction abnormalities after transcatheter aortic valve implantation with the Medtronic-CoreValve and the effect on left ventricular ejection fraction. Am J Cardiol 2011;107:285-289.

26 Houthuizen P, van Garsse LA, Poels TT, de Jaegere P, van der Boon RM, Swinkels BM, Ten Berg JM, van der Kley F, Schalij MJ, Baan J Jr, Cocchieri R, Brueren GR, van Straten AH, den Heijer P, Bentala M, van Ommen V, Kluin J, Stella PR, Prins MH, Maessen JG, Prinzen FW: Left bundle-branch block induced by transcatheter aortic valve implantation increases risk of death. Circulation 2012; 126:720-728.

27 Spethmann S, Dreger H, Baldenhofer G, Stüer K, Saghabalyan D, Müller E, Hättasch R, Stangl V, Laule M, Baumann G, Stangl K, Knebel F: Short-term effects of transcatheter aortic valve implantation on left atrial mechanics and left ventricular diastolic function. J Am Soc Echocardiogr 2013;26:64-71.

28 Aslan S, Gul M, Cakmak HA, Ozturk D, Celik $\mathrm{O}$, Satilmisoglu MH, Gode S, Tasbulak O, Yildirim A, Bakir I: Short-term effects of transcatheter aortic valve implantation on left atrial appendage function. Cardiol J 2015;22: 527-534. 